\title{
Oxazoline-Based Hydro-, Amphi- and Lipogels from Microwave-Assisted Synthesis
}

\author{
F. Wiesbrock $^{1}{ }^{1}$, A. HeCke ${ }^{2}$, B. Wirnsberger ${ }^{1}$, A. M. Kelly ${ }^{2}$, F. Stelzer ${ }^{1}$ \\ ${ }^{1}$ Graz University of Technology, Institute for Chemistry and Technology of Materials, Stremayrgasse 16, \\ AT-8010 Graz, Austria. \\ ${ }^{2}$ Polymer Competence Center Leoben GmbH (PCCL), Roseggerstrasse 12, AT-8700 Leoben, Austria. \\ E-mail: f.wiesbrock@tugraz.at (F.Wiesbrock)
}

Sci Pharm. 2010; 78: 660

doi:10.3797/scipharm.cespt.8.PMS33

The group of poly(2-oxazoline)s has scarcely been considered as scaffold for hydrogels [1,2], despite of the FDA approval for two prominent congeners, namely poly(2-ethyl-2-oxazoline) and poly(2-phenyl-2-oxazoline) (21 CFR 175.105). The polymerization of 2-oxazolines has significantly benefited from the advent of microwave reactors specially designed for chemical syntheses by a remarkable decrease of reaction times with a factor of 60 , maintaining the livingness of the polymerization $[3,4]$. These accelerations have paved the way to the synthesis of hydro-, amphi-, and lipogel libraries.

In this presentation, the influence of the ratio of poly(2-ethyl-2-oxazoline) vs. poly(2-phenyl-2-oxazoline), the degree of cross-linking and the type of crosslinker on the swelling degree and the proton-mediated degradation of the gels will be shown, and the potential of 2oxazoline-based gels as toolbox for tailor-made hydro-, lipo- and amphigels

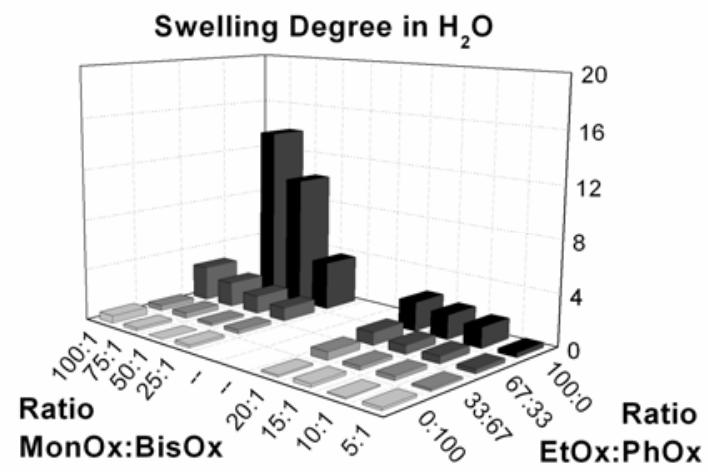
will be discussed [5].

[1] Chujo Y, Sada K, Matsumoto K, Saegusa T. Synthesis of nonionic hydrogel, lipogel, and amphigel by copolymerization of 2-oxazolines and a bisoxazoline. Macromolecules. 1990; 23: 1234-1237. doi:10.1021/ma00207a002

[2] Puskas JE, Chen Y. Biomedical Application of Commercial Polymers and Novel PolyisobutyleneBased Thermoplastic Elastomers for Soft Tissue Replacement. Biomacromolecules. 2004; 5: $1141-$ 1152. doi:10.1021/bm034513k

[3] Wiesbrock F, Hoogenboom R, Schubert US. Microwave-Assisted Polymer Synthesis: State-of-the-Art and Future Perspectives. Macromol Rapid Commun. 2004; 25: 1739-1764. doi:10.1002/marc.200400313

[4] Wiesbrock F, Hoogenboom R, Leenen MAM, Meier MAR, Schubert US. Investigation of the Living Cationic Ring-Opening Polymerization of 2-Methyl-, 2-Ethyl-, 2-Nonyl-, and 2-Phenyl-2-oxazoline in a Single-Mode Microwave Reactor. Macromolecules. 2005; 38: 5025-5034. doi:10.1021/ma0474170

[5] Hecke A, Wirnsberger B, Kelly AM, Stelzer F, Wiesbrock F; submitted. 